\title{
O Estado e a Educação Religiosa: Observações a partir da Psicologia
}

\author{
Geraldo José de Paiva ${ }^{1}$ \\ Universidade de São Paulo
}

\begin{abstract}
RESUMO - O tema da educação religiosa oferecida pelo Estado é tratado do ponto de vista das condições psicológicas adequadas a sua eficiente ministração, a saber, estabelecimento de relações interpessoais no pequeno grupo, nitidez na apresentação das informações e inserção num grupo de referência mais abrangente. Como base filosófica, necessária ao ponto de vista psicológico, é apresentada a visão de Habermas e Ratzinger do Estado democrático, cuja função é não só tolerar mas promover a diversidade cultural dos grupos que o compõem, sobre o pressuposto da ação comunicativa ou do diálogo.
\end{abstract}

Palavras-chave: psicologia da religião; educação religiosa; Estado democrático.

\section{The State and Religious Education: Psychological Remarks}

\begin{abstract}
Religious education offered by the State is dealt with from the point of view of the adequate psychological conditions to its efficient offering: interpersonal relations in the small group, distinctiveness of stimuli, and insertion into a broader reference group. As a philosophical basis, necessary to the psychological point of view, is presented Habermas'and Ratzinger's conception of a democratic State, whose function is not only to tolerate but to promote the cultural diversity of its component groups, following the presupposition of communicative action or dialog.
\end{abstract}

Key words: psychology of religion; religious education; democratic State.

A reflexão acerca do ensino religioso nas escolas públicas toca numa questão de fundo, filosófico e político, que no plano teórico se levantou a partir do amplo movimento da Aufklärung, e no plano prático se traduziu na separação entre a Igreja e o Estado ou, em outras palavras, na laicização do Estado, sequiela das revoluções do fim do século XVIII. Com a laicização, o Estado perdeu primeiro a vinculação com a Igreja, depois a vinculação com o divino, a seguir, no processo de secularização, a vinculação com o sagrado. Historicamente, contudo, houve várias re-apropriações do sagrado, derivadas do caráter absoluto que muitos atribuíram ao Estado.

Embora o ponto de vista destas considerações pretenda ser o da Psicologia, não se pode deixar de levar em conta o que foi denominado questão de fundo, pois a Psicologia é, em larga medida, uma ciência histórica.

Um ponto de partida possível para encarar essa questão de fundo é a posição de J. Habermas, expressa em algumas de suas intervenções recentes (Arens, 1993) e, em particular, no debate, de 2004, com o então Cardeal J. Ratzinger, acerca da fundamentação moral pré-política de um Estado liberal, ou democrático. Utilizaremos a tradução francesa do debate, publicada na revista Esprit (julho de 2004), porque não só o texto é compreensível, inclusive pelas anotações do tradutor Jean-Louis Schlegel (Schlegel, 2004), como seu conteúdo, contextualizado na cultura alemã contemporânea, é contraposto à esterilidade atual do conceito de laicidade na cultura francesa (Court, 2005). A implicação dessa contraposição para a cultura brasileira é óbvia, uma vez que a laicidade do

1 Endereço: Instituto de Psicologia da Universidade de São Paulo, Av. Prof. Mello Moraes, São Paulo, SP, Brasil 05508-900. E-mail: gjdpaiva@usp.br
Estado à francesa é invocada como princípio supremo em numerosos tópicos da vida jurídica nacional.

No debate travado na Academia Católica da Baviera, em Munique, aos 19 de janeiro de 2004, acerca dos fundamentos pré-políticos do Estado democrático, Habermas expressou-se claramente acerca do que constitui o caráter democrático de um Estado. É democrático, segundo Habermas, o Estado que possibilita e incentiva a expressão dos diversos grupos que o compõem. Essa possibilitação e esse incentivo dizem respeito, também, à convicção religiosa e às manifestações desta convicção. Segundo Habermas, a democracia republicana, de índole kantiana, que ele abraça, fundamenta-se na livre pactuação obtida pela ação comunicativa entre as pessoas. Parece que é no nível da fundamentação, e não nas derivações de um Estado democrático, que há parcial divergência entre Habermas e Ratzinger. Habermas considera a ação comunicativa como o princípio ético, ao passo que Ratzinger ainda se pergunta pela fundamentação ética da ação comunicativa. Em outras palavras, a fundamentação ética é intrínseca ao agir comunicativo, segundo Habermas, e extrínseca a ele, segundo Ratzinger. Uma vez, contudo, estabelecido o caráter democrático do Estado, um e outro não se contentam com a posição absenteísta do Estado em relação à diversidade de seus grupos componentes, mas, ao contrário, entendem como devendo ser positiva a ação do Estado na promoção das peculiaridades culturais de seus grupos. Há, pois, no posicionamento do filósofo de Frankfurt e no do então cardeal coincidência quanto ao respeito e à promoção da diversidade. $\mathrm{O}$ respeito à diversidade conduz à defesa da liberdade, enquanto nada se impõe contrário à convicção de pessoas e grupos; a promoção da diversidade conduz igualmente à liberdade, enquanto se possibilitam as variadas expressões das culturas e subculturas sociais. Haverá, claramente, regiões 
de conflito, uma das quais, e das mais importantes, é a do critério da maioria nas decisões coletivas. O essencial, contudo, é o princípio e a contínua ação comunicativa, segundo Habermas, ou a continuidade do diálogo, segundo Ratzinger. Percebe-se, pois, como a laicidade do Estado, que deve ser mantida para não se repetirem confusões como a do poder temporal dos papas ou a do poder espiritual dos príncipes, não se define mais como combate ao religioso nem como tolerância ao religioso, mas como abertura à pluralidade religiosa, no seio da abertura à pluralidade cultural de grupos e pessoas que compõem o Estado.

Estas posições, de caráter filosófico, são cruciais para os dias de hoje, em particular no Ocidente. É, com efeito, lugar comum o qualificativo de "plural" para o Estado e para a sociedade ocidental contemporânea. Um dos inesperados efeitos do processo de globalização, ou mundialização, está sendo, exatamente, o revigoramento de peculiaridades culturais e subculturais de toda espécie, a multiplicidade de modos de vida acolhidos pelo Estado e pela sociedade.

Ora, uma das convicções mais importantes de grande parte, senão da maioria, da população é a convicção religiosa. Ao Estado democrático cabe não só se abster de impedir sua manifestação mas, segundo Habermas e Ratzinger (2004), apoiar positivamente sua expressão. Se o Estado assume a tarefa de prover educação e instrução, levanta-se a questão da educação e da instrução religiosas proporcionadas pelo Estado. Essa é uma difícil questão, entre outras razões porque tributária de uma confusa história de relações entre Igreja e Estado. Provavelmente não há um encaminhamento ideal $a$ priori do problema, mas, ao contrário, é na ação comunicativa, ou no diálogo, que se pode chegar a um consenso, sempre renovável, quanto à equilibração dos dados da questão.

Há países, como a Holanda, que resolveram o problema confiando o ensino religioso às instituições educacionais religiosas, financiadas pelo Estado. Na Bélgica, as Universidades católicas e "livres", isto é, não confessionais, são sustentadas pelo Estado, e o ensino fundamental público ministra aulas de religião católica, judaica, islâmica e "laica", de responsabilidade das respectivas instituições religiosas ou laicas. Enfatize-se que a instrução religiosa abrange também o sistema de convicções morais não-religiosas apresentadas por agrupamentos laicos. Esses países não conhecem, como o Brasil, uma pluralidade tão múltipla de religiões e, desse ponto de vista, torna-se viável oferecer, na escola pública, instrução religiosa destinada às poucas confissões e à laicidade. Naturalmente, no Brasil, onde as religiões se contam às dezenas, há o problema prático, possivelmente até de horário e de espaço físico, para atender igualmente a todas as expressões religiosas. A solução, no Brasil, tem sido a de proporcionar aos alunos, em particular aos do ensino fundamental, uma visão histórica, antropológica, por vezes psicológica e/ou filosófica das religiões, deixando-se às instituições propriamente religiosas a incumbência de formar na respectiva fé seus respectivos membros.

Ora, é contra esse modo de encaminhamento que, parece, se orienta o entendimento de Habermas e Ratzinger (2004) do que deve ser a ação de um Estado democrático. Há três razões fundamentais para a insuficiência desse encaminhamento: (1) não se provê ensino religioso mas ensino histórico, antropológico, científico das religiões; (2) o ensino propor- cionado não satisfaz a nenhuma religião concreta, uma vez que religião não é um conjunto de conhecimentos mas uma atitude, que inclui conhecimentos, afetos e predisposições de ação; (3) uma atividade limitada à instrução não corresponde à educação, para a qual existe um ministério específico.

Considere-se cada uma dessas razões.

(1) A História, a Antropologia e outros tratamentos científicos dados à religião são, por certo, úteis no estudo da religião. Embora, como empreendimentos científicos, esses tratamentos não se situem no mesmo nível epistemológico da religião, são capazes de destacar, na percepção dos alunos, muito mais o que as religiões têm em comum do que o que têm em separado. Com isso, podem fomentar a tolerância e a cooperação, sobretudo se, como se verá adiante, houver uma verdadeira educação religiosa, que passe da cognição a tarefas concretas. Não há, porém, apenas vantagens na abordagem científica. Dependendo do desenvolvimento cognitivo/afetivo dos alunos, a tendência à homogeneização do "religioso" e sua fácil transposição para o "sagrado" e, atualmente, para o "espiritual", situa a religião num grau de abstração que não corresponde à experiência que os alunos têm da realidade religiosa.

De outro lado, nem sempre os docentes formados em História, Antropologia ou Psicologia da religião conseguem manter a consciência dos níveis epistemológicos em que os alunos transitam de uma consideração científica da religião para uma consideração religiosa da religião. Pode haver uma sutil sugestão de que, ao fim e ao cabo, o realmente sagrado seja a ciência da religião... Há também a possibilidade de se afrouxar o laço de lealdade à própria cultura religiosa, substituindo-o pela indiferença.

(2) O ensino religioso não é simples transmissão de conhecimentos, isto é, de doutrinas ou de acontecimentos ligados à história da religião, mas um conjunto articulado de cognições, de afetos e de predisposições de ação, em outras palavras, o que tecnicamente se denomina "atitude". Outra maneira de se dizer isso é referir-se ao ensino religioso como "educação". Ensinar religião é, então, ensinar "atitude" religiosa ou transmitir uma "educação" religiosa.

Neste aspecto, o ensino da religião seria muito mais semelhante ao ensino da arte (Pruyser, 1976) e ao ensino da ciência no laboratório ou no campo do que a uma aula teórica. Pruyser, em particular, trabalha com os constructos habilidade, imaginação e ilusão, da teoria da arte, aplicandoos ao entendimento da religião (Paiva \& cols. 2004). Essa consideração remete, em particular, ao componente de ação na atitude. A religião, com efeito, é culto e prática. Por esta razão, o ensino da religião envolve, em algum momento, celebração e empenho concreto. Certamente isso supõe, da parte do professor da disciplina, uma preparação pessoal semelhante à do artista e do experimentador.

(3) Instrução não é toda a educação. Educação inclui conhecimento, cultivo do sentimento, padrões de valor, relações interpessoais sadias. $\mathrm{O}$ que hoje se espera das escolas, a saber, a educação para a cidadania, espera-se também do ensino religioso, uma educação religiosa. Famílias há que não se sentem em condição de passar essa educação aos filhos e que, por uma razão ou outra, 
não se valem dos recursos oferecidos diretamente pelas instituições religiosas. Para essas famílias, como mostra a pesquisa de Haaf e Timmermans (1986), na Holanda, a escola é desejada como instância que assume parcialmente o papel que tradicionalmente cabe à família.

Se é correta a concepção que Habermas e Ratzinger (2004) têm do Estado democrático, cabe ao Estado, apesar das dificuldades, ensejar e promover as culturas religiosas das pessoas e grupos em função dos quais existe, incluindose nessas culturas o laicismo, o agnosticismo e o ateísmo. Uma forma, de ensejar e promover as expressões religiosas é, sem dúvida, o ensino religioso, entendido no sentido de atitude e de educação. É conveniente insistir que mesmo o ateísmo, se esclarecido, integra o diálogo plural do Estado democrático e é portador de conhecimentos, sentimentos e valores que honram a humanidade. Nesse entendimento, justifica-se, novamente apesar das dificuldades, o que o legislador brasileiro dispôs quanto à oferta obrigatória do ensino religioso para a escola, embora facultativo para o aluno. E se justifica também tanto a supervisão deste ensino por parte do Ministério e das Secretarias de Educação como a responsabilidade pela remuneração dos professores.

\section{Ensino religioso e condições psicológicas}

Na Conferência internacional "Educação do Futuro - Desenvolvendo o Talento e a Criatividade", realizada em São Paulo em 1993 e patrocinada, dentre outros organismos, pela UNESCO, pelo MEC e pelo CNPq, discutiu-se a questão de se haveria futuro para a religião na educação do futuro (Paiva, 1995). Depois de mostrado, com dados estatísticos de crescimento e declínio de algumas religiões, do agnosticismo e do ateísmo, que religião e irreligião não são necessidades psicológicas, mas são atitudes aprendidas socialmente na cultura, destacou-se a importância das relações interpessoais no grupo pequeno, da exigência de nitidez na apresentação das informações e da inserção num grupo de referência mais abrangente. Essas são perspectivas psicológicas acerca do futuro da religião, aqui retomadas e desenvolvidas em relação ao ensino religioso.

O contexto sociocultural do ensino religioso é o contexto adequado da presente discussão, uma vez que é a instituição escolar que ministra esse ensino a uma população filiada a várias tradições culturais de adesão ou não-adesão religiosa. Esse, aliás, é o clima costumeiro da inserção em uma religião ou da deserção dela. Não se pode, tampouco, esquecer que a religião e a irreligião, em muito maior escala do que, por exemplo, a Física, tem sua realidade estabelecida pelo intercâmbio e pelo consenso social. Em outras palavras, são realidades que vão adquirindo sua aparente "naturalidade" ao longo de processos que incluem modelo e imitação, conversação, denotações cognitivas e também conotações emocionais, sistemas de aprovação grupal, desempenho de papéis, construção de identidade psicossocial.

Como realidades socioculturais, religião e irreligião têm muito em comum com a linguagem, verbal e não-verbal, no processo de sua aquisição, transformação e perda. Anteriormente a algum detalhamento psicológico do tema, é de grande utilidade recordar a estrutura multifatorial de religião, estabelecida há tempo pelos sociólogos C.Y. Glock e R. Stark (1962). Estes autores descobriram, por meio da análise fatorial, que "religião", no cristianismo que investigaram, não é um termo unidimensional, uma vez que no uso comum pode referir-se a cinco dimensões distintas, embora correlacionadas em maior ou menor grau. Essas dimensões são as seguintes: a ideológica ${ }^{2}$, a ritual, a experiencial, a intelectual e a conseqüencial. A mais importante delas, de acordo com o grau de correlação, é a dimensão ideológica, que consiste na convicção de fé e manifesta-se, por exemplo, na devoção e na prece.

Secundariamente, a religião é uma participação ritual, um conjunto de conhecimentos, uma experiência e uma ordenação moral da vida. Se o ensino religioso visa a transmissão de doutrinas ou fatos, limita-se a uma dimensão secundária da religião, a saber, a intelectual. Se visa a fornecer diretrizes morais, permanece, igualmente, numa dimensão secundária, que estudos posteriores vieram expurgar da definição. $\mathrm{O}$ ensino religioso deveria, pois, visar a dimensão essencial, denominada ideológica, que é a adesão de fé. Independentemente da modalidade religiosa, a fé, a devoção, a prece, numa palavra, a ligação com Deus, é o núcleo da religião, como sua ausência é o núcleo da irreligião.

São estes elementos que uma pesquisa histórica, antropológica, psicológica ou outra deveria buscar nas formas religiosas que estuda ou, mesmo, nos elementos comuns que extrai das formas religiosas. Ainda melhor, o ensino religioso, ministrado no sentido amparado na concepção de Habermas e Ratzinger (2004) do Estado democrático, deveria visar o desenvolvimento da atitude de fé e de suas manifestações, como as várias formas de prece e a convicção da ligação com Deus. Ora, estamos aqui longe de um ensino de "doutrinas" ou de uma "moral". Como a fé não se dá no vácuo, há elementos cognitivos e doutrinais na adesão a Deus; porém o essencial é a adesão. Do ponto de vista psicológico, essa adesão, visada pelo ensino religioso, supõe adequadas relações interpessoais num grupo, com a proposição de modelos de adesão, senso de inserção numa história mais ampla, constituição de uma identidade grupal.

\section{Importância das relações interpessoais}

As relações interpessoais supõem proximidade das pessoas. Embora os papéis grupais sejam diferentes, induzindo com isso certa distância entre as pessoas, os papéis complementares, como os de pais e filhos, professor e aluno, tendem a induzir proximidade entre os parceiros de papel. A proximidade por si só não denota relações positivas de ordem cognitiva ou afetiva, mas é condição de estabelecimento dessas interações, sejam elas cognitivas ou afetivas. A interação cognitiva positiva se dá pelo diálogo, termo tradicional que vem ao encontro da ação comunicativa.

O ensino religioso, do ponto de vista cognitivo, para ser significativo deve corresponder-se com o elemento afetivo do desejo. Esse elemento pode ser despertado ou, se já presente, intensificado, por meio do diálogo. É importante dar-se conta

2 A expressão "ideologia" não tem a acepção marxista, mas diz respeito à convicção de fé que tem lugar na intimidade da pessoa, e foi assimilada às "idéias", por Glock e Stark, com a preocupação de neutralidade científica (Vergote, 1997) 
de que o desejo, no caso de apreender um sentido profundo para a vida, moldado dentro de uma tradição cultural na qual a pessoa já foi introduzida, só pode alimentar-se com o diálogo se, no caso do ensino religioso, aluno e professor estiverem imbuídos desse desejo. Parece, pois, inoperante o esforço do professor que não se pergunta pela dimensão religiosa ou, mais simplesmente, que não ama a religião. Parece, também, inoperante esse esforço se não vai ao encontro de um desejo religioso por parte do aluno. Nesse ponto parece ainda adequado dizer que "a educação religiosa dos filhos (ou alunos) é a continuada educação religiosa dos pais (ou professores)" (Paiva, 1995, p. 375).

Em termos práticos, encontros pessoais em grupos menores são uma condição necessária, embora não suficiente, para a eficácia do ensino religioso. Nesses grupos menores, aliás, torna-se possível um outro processo, não necessariamente interpessoal mas, em todo o caso, social, a saber o da imitação. A religião, enquanto referência fundamental da cultura, como a linguagem, as boas maneiras, as expressões emocionais, "se tece no dia-a-dia, muito mais pelo modelo fornecido do que por injunções verbais explícitas ou por conseqüências artificialmente dispostas" (Paiva, 1995, p. 374). São as relações interpessoais que possibilitarão, do ponto de vista psicológico, a dimensão de relação pessoal com Deus, a primeira e mais definidora dimensão fatorial da religião.

\section{Nitidez na apresentação das informações}

O ensino religioso tem um componente cognitivo essencial, correspondente à dimensão intelectual da definição fatorial de Glock e Stark (1962). Fazem parte dela os elementos doutrinais, sua inter-relação, o conhecimento da história do grupo religioso, e tópicos assemelhados. Como em qualquer aprendizagem cognitiva, a nitidez dos estímulos apresentados é essencial. Não é possível, por exemplo, aprender-se psicanálise confundida com behaviorismo. Os conceitos de uma e de outro só se tornam apreensíveis quando não fundidos. Tanto os conceitos individuais de uma teoria como sua articulação pertencem a uma família cognitiva estabelecida segundo critérios discriminadores. Esses critérios fornecem o protótipo do objeto de conhecimento, juntando os elementos que lhe correspondem e separando os elementos que não lhe correspondem (Rosch, 1978). Na dimensão do contraste, naturalmente, os elementos estranhos ao protótipo podem ser de grande utilidade, enquanto contribuem exatamente para a maior nitidez do protótipo. Nesse sentido, psicanálise e behaviorismo podem ser ensinados juntos não porque componham o mesmo protótipo, mas porque o protótipo da psicanálise contrasta com o do behaviorismo.

Não haveria, no entanto, possibilidade de behaviorismo e psicanálise serem propostos dentro de um protótipo único? A possibilidade existe, desde que o princípio de organização não seja o simples contraste, mas o metacontraste (Oakes, Haslam \& Turner, 1998), como quando o estudo psicológico do ser humano se contrapõe a seu estudo biológico ou físico. Essas considerações se aplicam ao ensino religioso. As religiões não se equivalem do ponto de vista cognitivo, isto é, uma religião não é outra. As concepções, as doutrinas, as histórias são, sob certo aspecto, nem mesmo específicas, mas singulares. Não é possível ensinar o budismo como se fosse o cristianismo, como não é possível ensinar o protestantismo luterano como se fosse o catolicismo.

Estará o ensino religioso nas escolas apetrechado para a singularidade conceitual das numerosas religiões existentes no Brasil? A resposta não pode ser genérica: há de ser regional ou mesmo sub-regional, levando em conta a incidência das adesões religiosas dos alunos. Se a decisão pelo protótipo obedecer não simplesmente ao princípio do contraste, mas ao do metacontraste, o encaminhamento da resposta pode tornar-se mais simples: cristianismo e budismo, por exemplo, são mais distantes um do outro do que catolicismo e protestantismo, ou do que as múltiplas ramificações do budismo. $\mathrm{O}$ ensino religioso não deixaria de propor, com nitidez, os critérios discriminadores de um e outro protótipo ampliado. Não há como obliterar, no entanto, a dificuldade da aquisição de competência, por parte dos docentes, de protótipo religioso tão complexo como o cristianismo em geral ou o budismo em geral.

Haveria, no entanto, um terceiro nível, mais abstrato, de protótipo religioso, enquanto religião seria contrastada, por exemplo, com ciência ou política ou economia. É possível, até, que é nesse nível mais abstrato que muitos encaram a real factibilidade de ensino religioso nas escolas, como disposto na legislação. Nesse nível, contudo, ainda seria necessário manter a nitidez dos conceitos e contrastar religião de outras perspectivas humanas. É óbvio que quanto mais se sobe na abstração, menos viva e vivida se torna uma realidade. Isso não significa que não haja mérito e vantagem na apresentação abstrata, desde que nítida.

Um efeito, como já apontado, pode ser a tolerância e o empenho por elevadas causas comuns. No entanto, o mínimo denominador comum nem sempre é o mais indicado para toda finalidade, como quando se quer conhecer e apreciar uma bebida ou uma obra de arte. Nesse nível é possível agrupar as religiões a espiritualidade e a moralidade, embora com o risco de se agruparem coisas conceitualmente distintas, uma vez que religião inclui alguma forma de transcendência, ao passo que espiritualidade e moralidade podem situar-se no âmbito da imanência humana. É provável que nesse agrupamento mais inclusivo se perca a nitidez da apresentação dos estímulos informativos, e dissolva-se o fundo contra o qual se destaque perceptualmente alguma figura com contorno.

\section{Inserção num grupo de referência mais abrangente}

Não bastam as relações interpessoais, que se dão no pequeno grupo social, nem a nitidez da proposição das informações para se garantir a estabilidade da formação religiosa que se pretende favorecer com o ensino religioso nas escolas. O princípio geral da necessidade de inserção num grupo de referência mais amplo no tempo e no espaço, ou seja, não apenas num movimento, mas numa instituição religiosa, diz respeito à estabilidade proporcionada pelo consenso. Esse consenso social, que garante a maior parte das chamadas realidades da vida humana, tem-se dado de muitas maneiras ao longo da história.

Em nossos dias, em que o pluralismo é um dos vetores da cultura e da sociedade, o consenso não se dá por imposição da força ou pela ausência de alternativas. Em termos 
do debate Habermas e Ratzinger (2004), pode-se dizer que o consenso se dá pela ação comunicativa ou pelo diálogo. Ainda assim, o pluralismo não é o único vetor da dinâmica sociocultural contemporânea. O processo de globalização tem mostrado a ressurgência, quando não a insurgência, de consensos mais limitados, freqüentemente de natureza étnica e religiosa, com fortes componentes de lealdade histórica, que equilibram vetorialmente a dinâmica social. Esse reequilíbrio se faz notar, muito particularmente, na questão da identidade. Não se trata, porém, de reinstalar um equilíbrio estático. Provavelmente a idéia de um equilíbrio como esse em alguma época da história humana é uma falácia. Em nossos dias seria, certamente, uma falácia.

A inserção num grupo mais abrangente, ampliado no espaço e no tempo, garante o sentido de identidade, isto é, de reconhecimento de uma realidade social também abrangente, que resistiu ao tempo e ao deslocamento espacial e que nos retira de uma solidão sem referências sólidas. O dinamismo da existência não permite que essa resistência se torne inércia: ao contrário, a história mostra as transformações por que passam as grandes identidades coletivas em contato com o ambiente e as transformações que, por sua vez, induzem no ambiente. Sob esse ponto de vista, o ensino religioso nas escolas não deveria limitar-se à escola. Para ser, além de ensino, educação, deveria tender à inserção no grupo religioso portador dessa referência dinâmica, isto é, estável e aberta ao diálogo com a diferença. O contato com os grupos locais ou regionais das filiações religiosas daria o tônus final para o ensino escolar.

\section{Conclusão}

O quadro esboçado, a partir do entendimento do que seria um Estado democrático contemporâneo e de algumas observações a partir da Psicologia, admite, certamente, graus de realização. O que certamente é importante é a reflexão acerca da conjuntura atual do ensino religioso nas escolas. Melhor do que conjuntura pode-se dizer estrutura, pois embora haja variáveis conjunturais em todo planejamento e decisão, às vezes não há clareza a respeito da estrutura da realidade que se quer ordenar. Habermas e Ratzinger (2004) não são ingênuos em relação ao ideal da ação comunicativa ou do diálogo que propõem como base pré-política da convivência social no Estado democrático. A descrição de alguns processos psicológicos de aprendizagem social tampouco garante a efetivação dessa aprendizagem. Porém essas são contribuições que podem levar à reflexão acerca do que está em jogo, antes de se passar à ação ou à discussão dos caminhos que a ação já iniciou.

\section{Referências}

Arens, E. (Org.). (1993). Habermas et la théologie. Paris: Cerf. Court, R. (2005). Raison et religion. À propos de la discussion Jürgen Habermas-Joseph Ratzinger. Esprit, 317, 38-51.

Glock, C.Y. \& Stark, R. (1962). On the study of religious commitment. Religious Education, 57. Research Supplement, 98-110.

Haaf, N. ten \& Timmermans, C. (1986). Wetenschap en levensbeschouwing: een verkenning naar de verhouding tussen wetenschap en levensbeschouwing. Nijmegen: Katholieke Universiteit Nijmegen.

Habermas, J. \& Ratzinger, J. (2004). Pluralisme et Morale. Esprit, 306, 6-28.

Oakes, P.; Haslam, A \& Turner, J. C. (1998). The role of prototypicality in group influence and cohesion: contextual variation in the graded structure of social categories. Em S. Worchel, J. F. Morales, D. Paez \& J. C. Deschamps (Orgs.), Social Identity: international perspectives (pp. 75-92). Londres: Sage publications.

Paiva, G. J. de (1995). Haverá futuro para a religião na educação do futuro? Reflexões a partir da Psicologia. Perspectiva Teológica, 27(73), 369-378.

Paiva, G. J. de, Garcia, A, Gonçalves, A K., Scala, C.T., Faria, D.G.R. de, Gómez, M. L.Trovato, Jordão, M. P., Barbosa, R.C .\& Franca, S.M.S. (2004). Experiência religiosa e experiência estética em artistas plásticos: perspectivas da Psicologia da Religião. Psicologia: Reflexão e Crítica, 17(2), 223-232.

Pruyser, P. W. (1976). Lessons from Art Theory for the Psychology of Religion. Journal for the Scientific Study of Religion, 15, 1-14

Rosch, E. (1978). Cognition and Categorization. Hillsdale, N.J.: L. Erlbaum Associates

Schlegel, J.-L. (2004). Les fondements prépolitiques de l'État démocratique. Esprit, 306, 5-6.

Vergote, A. (1997). Religion, Belief and Unbelief. A psychological study. Amsterdam/Atlanta: Rodopi.
Recebido em 22.11.2005

Aceito em 12.04.2006 